\title{
ENTRE GANHOS E PERDAS SIMBÓLICAS: A (DES) MOBILIZAÇÃO DAS ENFERMEIRAS QUE ATUARAM NA SEGUNDA GUERRA MUNDIAL
}

\author{
Between Profits and Symbolic Losses: The (De) Mobilization \\ of the Nurses who had Acted in The World War II \\ Entre Lucros y Perj uicios Simbólicos: La (Des) Movilización \\ de Las Enfermeras que Actuaron en la Segunda Guerra Mundial
}

Alexandre Barbosa de Oliveira

Tânia Cristina Franco Santos

\begin{abstract}
Resumo
Estudo histórico-social. Objetivos: descrever as circunstâncias que ensejaram a mobilização e a desmobilização do primeiro grupamento feminino de enfermagem do Exército que atuou no Serviço de Saúde da Força Expedicionária Brasileira durante a Segunda Guerra Mundial e analisar os efeitos simbólicos advindos da atuação deste grupamento. As fontes primárias constituíram-se de depoimentos orais, documentos escritos e/ou oficiais, jornais da época e biografias. As secundárias foram compostas do acervo bibliográfico existente sobre a referida temática. Os achados foram iluminados pelos conceitos de habitus e campo do sociólogo Pierre Bourdieu, que evidenciaram ganhos e perdas simbólicas processadas por ocasião da mobilização e da desmobilização destas voluntárias para a guerra. Conclui-se que das lutas simbólicas travadas, as enfermeiras acabaram sofrendo os reflexos da dominação masculina orquestrada no contexto político-social do Brasil à época, o que trouxe como conseqüência a (re) atualização de seu habitus.
\end{abstract}

Palavras-chave: História da Enfermagem. Enfermagem Militar. Memória.

\begin{abstract}
Descriptive and social study. Objectives: to describe the circumstances that had tried the mobilization and the demobilization of the first feminine grouping of nursing of the Army that acted in the Service of Health of the Force Brazilian Member of an expedition during World War II and to analyze the happened symbolic effect of the performance of this grouping. The primary sources had consisted of verbal depositions, written and/or official documents, periodicals of the time and biographies. The secondary ones had been composed of the existing bibliographical quantity on the thematic related one. The findings had been illuminated by the concepts of "habitus" and field of the sociologist Pierre Bourdieu, whom profits and processed symbolic losses for occasion of the mobilization and the demobilization of these volunteers for the war had evidenced. It was concluded that to stop symbolic fights, the nurses had finished suffering the consequences from the masculine domination orchestrated in the Brazil's political and social context at the time, what brought as consequence the update of its "habitus".
\end{abstract}

Keywords:

History of the Nursing. Military Nursing. Memory.

\section{Resumen}

Estudio histórico-social. Objetivos: describir las circunstancias que ocasionaron la movilización y la desmovilización del primer grupo femenino de enfermería del Ejército que participó del Servicio de Salud de la Fuerza de Expedición Brasileña mientras la Segunda Guerra Mundial ocurría y analizar los efectos simbólicos del funcionamiento de este grupo. Las fuentes primarias fueron declaraciones orales, documentos escritos, biografías y periódicos de la época. Las secundarias fueron compuestas del acervo bibliográfico que existe sobre la referida temática. Todo lo que fue descubier to fue iluminado por los conceptos de "habitus" y campo del sociólogo Pierre Bordieu, que evidenciaron lucros y perjuicios simbólicos por ocasión de la movilización y de la desmovilización de estas voluntarias para la Guerra. Se ha concluido que de las luchas simbólicas trabadas, las enfermeras acabaron sUfriendo los reflejos de la dominación masculina en el contexto político-social de Brasil a la época, lo que trajo como consecuencia la (re) actualización de sus "habitus".

Palabras clave:

Historia de la Enfermería. Enfermería Militar. Memorias. 


\section{INTRODUÇÃO}

Durante a Segunda Guerra Mundial (1939-1945), um grupo de enfermeiras treinadas pelo Exército Brasileiro foi enviado ao front a fim de prestar apoio de saúde aos soldados que iriam atuar nos campos de batalha da Europa. Essa participação, num conflito de ordem mundial, acabou por conferir a estas enfermeiras uma inserção profissional diferenciada em relação à das outras mulheres da sociedade brasileira da época.

A atuação delas foi tema de inúmeras publicações por parte da imprensa, que não se furtava em enaltecer a figura feminina como símbolo da Pátria-Mãe, valorizando simbolicamente aquelas enfermeiras que iriam cuidar dos soldados na guerra. Isso ocorreu num contexto político-social que privilegiava sobremaneira a propaganda, muita das vezes calcada em ritualizar elementos que deveriam ser veiculados como sustentação da ideologia totalitária anunciada pelo Estado Novo de Getúlio Vargas (1937-1945).

Contudo, logo após o término da guerra e antes mesmo de retornarem ao país, essas enfermeiras foram rapidamente desmobilizadas do efetivo do Exército. No bojo das circunstâncias que tornaram oportunas a mobilização e a desmobilização das Enfermeiras Febianas, configuraram-se, como conseqüências, ganhos e perdas simbólicas que acabaram por influenciar a (des) capitalização social delas no campo do Exército Brasileiro.

Diante dessa problemática, foram traçados os seguintes objetivos: descrever as circunstâncias que ensejaram a mobilização e a desmobilização do primeiro grupamento feminino de enfermagem do Exército para atuar no Serviço de Saúde da Força Expedicionária Brasileira (FEB) durante a Segunda Guerra Mundial e analisar os efeitos simbólicos advindos da atuação deste grupamento.

\section{ASPECTOS TEÓRICO-METODOLÓGICOS}

Trata-se de um estudo histórico-social, derivado do projeto de Dissertação de Mestrado em desenvolvimento intitulado "Signos do esquecimento: os efeitos simbólicos da participação das Enfermeiras da Força Expedicionária Brasileira na Segunda Guerra Mundial (1943-1945)", que, em observância ao previsto na Resolução 196/96 (sobre pesquisa envolvendo seres humanos), do Conselho Nacional de Saúde, foi submetido ao Comitê de Ética em Pesquisa da Escola de Enfermagem Anna Nery/Hospital Escola São Francisco de Assis em 26 de setembro de 2006, obtendo parecer favorável do mesmo. Apoiando este estudo, levamos em consideração a Lei 7.524, de 17/07/86, que assegura a liberdade de opinião para militares da reserva e reformados sobre pensamento e opinião política ou filosófica.

As fontes primárias foram obtidas através de depoimentos orais de duas Enfermeiras Febianas. Desta forma, utilizamos a História Oral Temática como método de investigação científica, dentro da perspectiva da História Nova, a qual traz novas perspectivas na construção dos trabalhos históricos, inclusive no que se refere à interpretação dos documentos escritos. Além dos depoimentos, foram utilizados também como fontes primárias: documentos escritos e/ou oficiais; jornais da época; e biografias das Enfermeiras Febianas.

Com relação às fontes secundárias, realizamos uma leitura crítica de teses, dissertações, trabalhos e artigos relacionados à temática, além de publicações de interesse ou que abordassem a História da Enfermagem Brasileira e História do Brasil.

Os dados foram iluminados pela Teoria do Mundo Social de Pierre Bourdieu, quando estuda como as estruturas se encontram interiorizadas nos sujeitos, constituindo um conjunto estável de disposições estruturadas que, por sua vez, estruturam as práticas e representações dessas práticas. Assim, os conceitos de habitus e campo fundamentaram a análise da inserção das Enfermeiras Febianas no campo do Exército Brasileiro, evidenciando ganhos e perdas simbólicas processadas pela mobilização e pela desmobilização destas voluntárias para a guerra.

\section{VOLUNTÁRIAS DA PÁTRIA PARA A GUERRA: A MOBILIZAÇÃO DO PRIMEIRO GRUPAMENTO FEMININO DE ENFERMAGEM DO EXÉRCITO}

A Segunda Guerra Mundial eclodiu no contexto do Estado Novo, deixando o Brasil numa situação delicada, pois, sob o governo autoritário de Vargas, viviam no país muitos simpatizantes dos alemães e seus coligados [italianos e japoneses]; por outro lado, havia um forte lobby próestadunidense em voga ${ }^{1}$.

Ao romper relações diplomáticas com os países do Eixo por pressões dos Estados Unidos, o Brasil acabou sofrendo uma série de torpedeamentos de vários navios. Por isto, o Estado conseguiu o convencimento e a adesão da população brasileira ao seu projeto belicista, o que foi facilitado pela ação do Departamento de Imprensa e Propaganda, inflamando na população 0 ardor patriótico, que culminou num amplo processo de adesão voluntária para combater os nazi-fascistas no teatro de operações europeu.

Neste sentido, várias iniciativas de mobilização civil para a guerra e de constituição de um front interno foram tomadas pelo governo. Muitas destas iniciativas foram, de fato, efeitos de mobilização ou efeitos de alinhamento pró-Estado Novo e, por extensão, pró-Aliados. Estas ações sobrepuseram objetivos políticos do Estado Novo e sua concepção de sociedade, e tomaram a guerra como um álibi e um modelo de sociedade militarizada. A constituição do front interno serviu, assim, à consolidação de uma ordem interna que tinha como modelos pedagógicos, por exemplo, escoteiros para os meninos e enfermeiras para as meninas, ambos entendidos como disponibilidade total de servir a um sistema de disciplina militar e de devoção incondicional à pátria².

Neste contexto, no dia 9 de agosto de 1943, através de portaria ministerial, foi criada a $1^{\text {a }}$ Divisão de Infantaria Expedicionária, força combatente da Força Expedicionária Brasileira, composta de unidades de infantaria, artilharia, engenharia e saúde, entre outras, que reuniu um total de 25.334 cidadãos, dos quais 15.069 integravam a tropa de combate, comandada pelo general-de-divisão João Baptista Mascarenhas 
de Moraes. Com este efetivo, a FEB participou ativamente das operações de guerra no teatro do Mediterrâneo, de julho de 1944 a maio de 1945, na campanha da Itália 3 .

O Serviço de Saúde da FEB contou com 166 médicos, 26 dentistas, 6 farmacêuticos, 44 enfermeiros, 6 manipuladores de farmácia, 6 manipuladores de radiologia, 2 protéticos, além de 67 enfermeiras, as quais formaram o primeiro corpo feminino de enfermagem do Exército Brasileiro ${ }^{4}$.

Estas enfermeiras formaram um grupo pioneiro dentro do Exército Brasileiro, pois foram as primeiras mulheres a participarem regularmente dos quadros do efetivo militar dessa Força, o que não foi bem visto pela sociedade em geral e nem aceito satisfatoriamente por segmentos do próprio Exército, que possuía em seu contingente, até então, apenas indivíduos do sexo masculino.

Essa insatisfação pode ser percebida no seguinte trecho:

A reprovação social veio a se revelar com toda força, quando a Sra. Santinha Dutra, esposa do ministro da Guerra, foi nomeada patrona das enfermeiras da FEB [pela Comissão de Assistência às Enfermeiras da FEB]. Às moças que Ihe levaram a notícia, ela apontou a porta da rua, dizendo em voz alta que era contra o fato de mulheres entrarem no Exército e que isso era coisa de moças que 'não prestavam'.. '.

0 ingresso destas mulheres no campo militar ocorreu graças à abertura do voluntariado pelo Exército para que, assim, fizessem parte do Serviço de Saúde da FEB. As mulheres que possuíam qualquer experiência na área de Enfermagem poderiam ou não aceitar a convocação; todavia, um forte apelo patrítico esteve presente na propaganda veiculada pela mídia da época, que anunciava a possibilidade, para a mulher, de ingresso num campo eminentemente masculino ${ }^{6}$. Como exigência no processo seletivo, era necessário portar diploma de Escola de Enfermagem, possuir idade entre 22 e 45 anos e ser solteira, viúva ou desquitada ${ }^{7}$.

A inclusão de enfermeiras brasileiras na FEB foi realizada através da solicitação do comando do V Exército Americano ao Exército Brasileiro, sob a alegação de melhor atender aos soldados brasileiros feridos e doentes, que baixassem nos hospitais militares durante a guerra. Desta forma, esta inclusão aliviaria a demanda de profissionais de Enfermagem para atender a tropa brasileira, em relação ao efetivo de enfermeiras norte-americanas, as quais já se encontravam atuando há cerca de quatro anos no conflito junto ao $V$ Exército Americano ${ }^{8}$. Havia também a considerar as previsões acerca dos futuros problemas relacionados às barreiras lingüísticas entre os soldados brasileiros a serem assistidos pelas enfermeiras norte-americanas.

Assim, as enfermeiras brasileiras estariam destinadas a cumprir o seu papel assistencial, já que, culturalmente, a função da Enfermagem era designada às mulheres. Essa função social posicionou-se como uma extensão dos afazeres maternos, uma vez que o zelo maternal se identificava, e muito, com a condição de cuidar dos filhos da Pátria-Mãe que possivelmente sofreriam com as morbidades advindas da guerra.

Uma vez concluída a seleção das voluntárias foi realizado o Curso de Emergência de Enfermeiras da Reserva do Exército
(CEERE). Durante este curso, que tinha caráter obrigatório, as enfermeiras tiveram que passar por um intenso treinamento militar, onde se procurou nelas incutir, através de ações pedagógicas próprias, o habitus militar, através de instruções teóricas, práticas hospitalares, e de intenso treinamento físico. Dessa forma, o Exército Brasileiro pôde impor seu veredicto mediante um arsenal de métodos, uma rígida disciplina e censura do campo, de modo a orquestrar um habitus militar para suas enfermeiras. Após o CEERE, as enfermeiras foram classificadas e nomeadas "Enfermeiras da Reserva de $3^{\text {a Classe do }}$ Exército", categoria esta criada para a incorporação destas mulheres, a qual não conferiu à selecionada titulação de posto militar 9 .

Após o envio das Enfermeiras Febianas à guerra, e quando já se encontravam nos hospitais de campanha, as nurses norteamericanas, que eram oriundas de um país desenvolvido e líder no mundo ocidental, além de serem possuidoras de maior capital cultural [militar e de enfermagem], acabaram por posicionar as enfermeiras brasileiras num plano hierarquicamente inferior, posto que as americanas possuíam patentes de major ou capitão e chefiavam os serviços de enfermagem dos hospitais de campanha. Em parte, esta situação foi reflexo do posicionamento do Exército Brasileiro em não conferir a estas mulheres o posto militar e uma remuneração condizente no momento da criação e da organização do quadro, o que desfavoreceu, supostamente, a adesão de D. Laís Neto dos Reys (diretora da Escola Anna Nery à época) no processo seletivo das candidatas ${ }^{10}$.

A posição desvantajosa das enfermeiras brasileiras nos hospitais do front italiano decorreu de fatores envolvendo competência técnica, inserção no Serviço de Saúde, domínio do idioma oficial, aparência pessoal [padrão étnico, qualidade dos uniformes e da lingerie, hábitos de consumo], além das questões hierárquicas. As enfermeiras brasileiras passaram a usar os produtos dos americanos, tais como uniformes, equipamentos, medicamentos, artigos de toalete etc, o que acabou por influenciar simbolicamente na configuração de sua prática, viabilizada por essa participação conjunta entre os serviços de saúde dos dois países ${ }^{11-12}$.

Há que se considerar que nunca antes mulheres brasileiras haviam sido convocadas de forma tão enfática a alinhar-se do lado de uma tropa para um conflito de ordem mundial como fora a Segunda Guerra Mundial, combinando treinamento rigoroso, sentimento nacionalista, prontidão, alerta e marcha e fundindo ideais do Estado Novo com a mobilização para a guerra, guerra externa contra o nazi-fascismo, a favor da nova ordem mundial e em nome de um ideal de brasilidade construído no negativo dos estrangeiros. Mas, sobretudo, mobilização permanente que o Estado Novo estava, pretensamente, a erigir.

\section{A (DES) CAPITALIZAÇÃO SIMBÓLICA ADVINDA DA DESMOBILIZAÇÃO DAS ENFERMEIRAS FEBIANAS}

Em julho de 1945, enquanto a FEB aguardava seu regresso ao Brasil, o governo, percebendo que a nova visão de mundo dos expedicionários poderia ser incompatível com a do Estado Novo, resolveu, então, desmobilizar a Força Expedicionária Brasileira, que ainda se encontrava na Europa ${ }^{13}$. 
Esta ação foi resultado de uma preocupação com as possíveis consequêencias da chegada da FEB ao Brasil, vitoriosa e prestigiada, e as repercussões políticas que traria, pois a força material ou simbólica que os agentes podem mobilizar na luta pelo exercício legítimo do poder depende, em cada estágio de sua posição na estrutura do campo, ou seja, da autoridade e da força capitalizada no decorrer das lutas ${ }^{14}$.

A desmobilização da FEB foi oficializada através do Aviso Ministerial 217-185, de 6 de julho de 1945. Sua dissolução foi articulada pelo general Eurico Gaspar Dutra [ministro da Guerra] e pelo general Góis Monteiro [chefe do Estado-Maior do Exército]. Nesse sentido, o Exército Brasileiro demonstrava a sua contribuição para o reforço simbólico da manutenção da ordem política e militar.

Confirmando o interesse político-militar em desmobilizar a FEB, uma enfermeira assim se expressou:

...0 comando geral, quer dizer o Dutra, deu 'barata voa' na FEB... O Getúlio tinha medo do pessoal da FEB, porque ela era uma tropa altamente treinada $e$ combateu a ditadura, e ele era um ditador! Quem era da ativa ele mandou pras fronteiras, pagar castigo nas fronteiras... Espalhou todo mundo! Equem era da reserva, na mesma hora foi pra rua! Entregava o material no quartel, e vai embora pra casa! (Enfermeira Elza Cansanção)

Acabava, assim, de forma frustrante, a participação de milhares de cidadãos, brasileiros e brasileiras, na força combativa de um grande evento histórico, que trouxe em seu bojo projeções político-sociais que produzem intensos reflexos até os dias atuais.

Após a desmobilização, os expedicionários foram proibidos de dar declarações públicas e até mesmo de andar uniformizados pelas ruas ou portar medalhas e condecorações. Essa proibição representou uma estratégia no sentido de impedir a visibilidade destes expedicionários, então porta-vozes autorizados a expressarem o discurso legítimo e consagrador acerca da sua participação na Segunda Guerra Mundial, uma vez que

o porta-voz autorizado é um objeto de crença garantido e certificado, o qual tem sua realidade expressa na aparência, porque sua realidade é garantida pela instituição e materializada pelo título, símbolos, galões, uniformes e outros atributos, e não em sua crença, ou menos ainda em sua pretensão singular ${ }^{15}$.

Logo após a chegada dos febianos ao Rio de Janeiro, foi determinado que eles desfilariam e ficariam aguardando, nos quartéis, suas dispensas e o pagamento dos soldos devidos, e então seriam dispensados, por fim. As novas ordens produziram as conseqüências políticas desejadas, pois poucos expedicionários se envolveram em política, no crepúsculo do Estado Novo ${ }^{16}$.

0 fragmento destacado a seguir ratifica esta idéia:

É... Não podiam andar fardados nem nada los febianos]... O Dutra era fascista, era nazista... Ele seguia a cartilha do Hitler... Todos eles ficaram com medo quando nós voltamos. Houve um pavor geral! (Enfermeira Elza Cansanção)
A atuação das Enfermeiras Febianas na guerra foi marcada por inúmeros elogios dos chefes militares aos soldados febianos, dos quais se depreende que sua contribuição teve um significado positivo para o êxito da campanha do Brasil na Segunda Guerra Mundial. No entanto, antes mesmo do seu retorno ao Brasil após o término da guerra, as enfermeiras também foram "desligadas" das fileiras do Exército Brasileiro sem qualquer explicação, sendo desmobilizadas pelo Governo Federal através do Exército, à semelhança de seus companheiros soldados da FEB, a fim de que não se cultivasse no país o "perigoso ideal febiano" de combater os regimes autoritários.

Sobre essa desmobilização uma das depoentes assim esclareceu:

... Quando nós chegamos aqui no Brasil, nós já viemos desmobilizadas. Nós já viemos da Itália desmobilizadas... Nós só fizemos entregar o material que tinha que entregar e tchau, tchau! Vai embora pra casa! Apresentamo-nos na Diretoria de Saúde e demos baixa. (Enfermeira Elza Cansanção)

A apresentação das Enfermeiras da FEB, depois de terminada a guerra, ocorreu no âmbito da Diretoria de Saúde, na Capital Federal. Por ocasião desta apresentação, uma das enfermeiras assim se expressou:

... apresentei-me na Diretoria de Saúde no Rio de Janeiro, era o general Souza Ferreira diretor de Saúde no Rio de Janeiro. Este não me deu a menor atenção! Ele estava escrevendo no gabinete. Nem levantou os olhos, mal me cumprimentou, e disse assim: 'Apresentese à $3^{a}$ Seção! Será desligada!' Eu, nessa hora, tive vontade até de chorar. Eu não esperava discurso, mas esperava um aperto de mão com a mão direita e um abraço de agradecimento... Encerrou, encerrou... Eles não deram satisfação! (Enfermeira Virgínia Portocarrero)

Ao ter desmobilizado as Enfermeiras da FEB, o Serviço de Saúde do Exército acabou por sofrer uma perda, pois deixou de ter em seus quadros um grupo de mulheres que incorporaram um capital cultural específico, pois experimentaram situações que contribuíram para a atualização de seu habitus profissional. Sobre este enfoque, uma das enfermeiras referiu o seguinte:

... Nós todas ficamos muito aborrecidas com a situação, porque era obrigação do Exercito nós termos continuado, e não ter jogado a gente na rua... Os hospitais [do Exército] necessitavam de nós! (...) Nós já tínhamos um treinamento grande! 0 nosso treinamento era como o de todas as Escolas de Enfermagem... Não tem uma profissional dessas daqui que tenha conhecimento da metade do que nós tivemos durante a campanha... (Enfermeira Elza Cansanção).

0 trecho acima ilustra o valor simbólico do autoreconhecimento acerca do capital cultural [de enfermagem de guerra e militar] que incorporaram as Enfermeiras da FEB por ocasião da sua atuação numa situação de campanha, em situações que exigiam prontidão intelectual e destreza profissional em situações de emergência clínica e cirúrgica. 
Apesar de possuírem um capital cultural inferior às enfermeiras diplomadas da época, a experiência que tiveram revelou-se como um lucro simbólico para o grupo.

No tocante à desmobilização das Enfermeiras Febianas, o conceito de poder simbólico pode ser aplicado à ação exercida pelo governo da época através do Exército Brasileiro, o que trouxe embutida uma violência simbólica. Assim, como conseqüência da desmobilização, ocorreu uma perda simbólica no campo militar ao desprestigiar as vivências angariadas pelas Enfermeiras Febianas na guerra. Contudo, alguns militares, entre eles o próprio general Marques Porto, que havia sido Comandante do Serviço de Saúde da FEB, chegaram a apoiar uma possível incorporação de enfermeiras militares no pósguerra às fileiras do Exército, mas essas iniciativas não chegaram a render as vantagens esperadas.

Em 18 de julho de 1945, chegou ao Rio de Janeiro o $1^{\circ}$ escalão de retorno da FEB, sob o comando do general Zenóbio da Costa, o qual foi recebido por uma das maiores manifestações cívico-populares de toda a nossa história. Este escalão desfilou na "Parada da Vitória" pelas principais ruas da capital por entre a multidão entusiasmada. Curiosamente, as Enfermeiras Febianas não participaram deste Desfile da Vitória.

Nesta chegada à então capital da República, os pracinhas foram recebidos com festa pela população, em manifestações de reconhecimento ao seu heroísmo. Nesta ocasião de chegada dos soldados brasileiros dos campos de batalha italianos expressouse o sentimento de culto aos heróis [vivos e mortos] da Pátria.

Assim, a presença do povo no Desfile da Vitória colocou em relevo a participação vitoriosa dos soldados febianos, e também representou uma estratégia do governo brasileiro e dos militares "mandatários do Estado, detentores da violência simbólica legítima" no sentido de capitalizar lucros simbólicos, mediante a liderança do grupo enviado para a Itália, uma vez que 0 poder sobre o grupo a que se pretende dar existência enquanto grupo é, ao mesmo tempo, um poder de fazer o grupo, pois a luta por posições de poder e prestígio envolve o reconhecimento dos outros que reside na oficialização do fato, aqui representado no ritual do desfile, cuja oficialização é levada a cabo pela nomeação pública, isto é, diante de todos.

Não obstante, o Desfile da Vitória no Rio de Janeiro conferiu prestígio ao grupo da Força Expedicionária Brasileira em um momento político dramático e intenso, quando se fazia praticamente iminente a deposição de Getúlio Vargas. Ademais, a imprensa da época, que noticiou ostensivamente esse evento, acabou por contribuir para tornar o grupo manifesto, pois as relações de comunicação são também relações de poder simbólico onde se atualizam as relações de força entre os produtores e os consumidores das informações, já que as relações sociais entendidas como interações simbólicas implicam no conhecimento e no reconhecimento do capital simbólico acumulado pelos agentes.

A respeito da exclusão das Enfermeiras Febianas no referido evento, uma das depoentes assim se expressou:

Nós não desfilamos quando chegamos aqui, e eles não convocaram a gente... Nós não fomos chamadas... Não convocaram as enfermeiras para desfilar! (Enfermeira Virgínia Portocarrero)
Essa exclusão das Enfermeiras Febianas do Desfile da Vitória reforça a diferença sexual existente entre os sexos relativa à ocupação dos espaços públicos, uma vez que a diferença entre os sexos não apenas diferencia, mas subordina e desiguala as mulheres em relação aos homens, considerada por Bourdieu uma forma de violência simbólica cujo habitus sexuado e sexuante, estruturante da visão e da divisão hierarquizante do mundo em masculino e feminino, opera, na interioridade dos agentes, fazendo-os agir de acordo com as disposições que lhes foram inculcadas ${ }^{17}$.

Assim, a sociedade moderna reproduz as grandes divisões sexuais, que em todo tempo e em toda parte estabelecem que os homens estejam coletivamente encarregados de manifestar o sagrado; talvez, por isso, se confirme a dominação masculina sofrida pelas enfermeiras, que não tiveram lugar no desfile ${ }^{18}$.

Além disso, no que se refere à presença de mulheres em guerras, a participação da mulher é requerida ou tolerada, porém na qualidade de ajudantes ou de enfermeiras, e acrescenta-se que, desde os tempos mais remotos, associa-se guerra e virilidade, paz e feminilidade. Desse modo, tanto a participação das enfermeiras na guerra como a sua exclusão do ritual alusivo a essa participação levam ao entendimento de que as guerras representam um espaço e um tempo de reafirmação da diferença sexual ${ }^{19}$.

0 recorte do depoimento abaixo evidencia algumas estratégias de resistência empreendidas pelas enfermeiras em face de sua exclusão do Desfile da Vitória:

Eu fui. Me fardei, e fui... Fiquei no meio do povo... Nós combinamos: Bem, nós vamos. Nós não vamos desfilar, mas vamos lá, porque o povo vai ver que nós fomos [à guerra]... (Enfermeira Virgínia Portocarrero)

Essas estratégias consistiram em uma tentativa de persuasão de sua identidade de enfermeira militar, mediante a utilização dos diferentes tipos de capitais acumulados em decorrência da participação na guerra, expressados através de representações objetais, aqui simbolizadas pelo uso do uniforme e dos emblemas de enfermeira militar.

No entanto, apesar da mobilização civil e do apelo suscitado na população quando do torpedeamento dos navios brasileiros a partir de 1941 e quando do retorno vitorioso dos expedicionários ao Brasil em 1945, a Segunda Guerra Mundial não atingiu plenamente a população brasileira, o que possivelmente explica o fato de o povo não ter sedimentado muito bem a importância daqueles participantes do conflito em tela. Haja vista que, pouco depois dos desfiles festivos, não existia mais, por parte da população, a demonstração clara do interesse em cultuarem os febianos, possivelmente por não ter ocorrido uma referência coletiva clara que permitisse estabelecer uma identificação evidente do povo com aquelas personagens.

Uma questão que chama a atenção diz respeito à forma como eram veiculadas as notícias publicadas no país sobre a participação das Enfermeiras da FEB, quase sempre em tom épico, sem revelar com mais detalhes as agruras e os problemas enfrentados advindos dos sofrimentos, da dor e da morte dos soldados brasileiros nos hospitais de campanha, além do aspecto profissional. Neste sentido, sua participação não chegou a ser 
tema dos debates sobre a atuação da FEB na guerra, o que fez com que a população não assimilasse bem o papel social a que teriam feito jus as moças que seguiram para o front.

Deste modo, ao terem sido desmobilizadas, as enfermeiras que compuseram a FEB foram também socialmente esquecidas, como se a presença destas não tivesse sido significativa para a campanha vitoriosa realizada pelas tropas brasileiras no solo italiano, o que dificultou o ( $\mathrm{re}$ ) conhecimento de suas atuações naquele que foi o primeiro grupo regularmente organizado de enfermeiras no Exército Brasileiro.

\section{CONCLUSÃO}

Os resultados evidenciaram que a aparição pública das Enfermeiras Febianas no campo social promoveu um ganho simbólico para a Enfermagem brasileira, determinado pelas circunstâncias de inclusão de um corpo feminino que foi incorporado de forma regular (ainda que deficiente) a uma estrutura militar que antes não admitia mulheres em seus

\section{Referências}

1. Ministério da Defesa(BR) Exército Brasileiro. Força Expedicionária Brasileira: 60 anos. [on line] 2004; [citado 25 dez 2004]. Disponível em: http//www.exercito.gov.br.

2. Cytrynowicz R. Guerra sem guerra. A mobilização e a constituição do 'front interno' em São Paulo durante a $2^{a}$ Guerra Mundial: 1939 1945 [tese de doutorado]. São Paulo (SP): Departamento de História/ FFLCH/USP; 1998.

3. Silveira JX. A FEB por um soldado. Rio de Janeiro (RJ): Ed Biblioteca do Exército; 2001.

4. SilvaAM. Serviço de Saúde do exército. Memorial. 2001. p. 114; p. 210-17.

5. Morais $B$ et al. Testemunho de uma enfermeira In: Depoimento de oficiais da reserva sobre a FEB. São Paulo (SP); 1949. p. 403-19.

6. Bernardes MMR. 0 grupamento feminino de enfermagem do exército na Força Expedicionária Brasileira durante $2^{\mathrm{a}}$ Guerra Mundial: uma abordagem sob o olhar fotográfico: 1942-1945. [dissertação de mestrado]. Rio de Janeiro (RJ): Faculdade de Enfermagem /UERJ; 2003.

7. Revista Nação Armada 1944 abr; 53: 120-21.

8. Cansanção E. E foi assim que a cobra fumou. $3^{\mathrm{a}} \mathrm{ed}$. Rio de Janeiro (RJ): Imago; 1987.

9. Cansanção E. Um! Dois! Esquerda! Direita! Acertem o passo! Maceió (AL): Cian Graf Ed; 2003.

10. A capitão enfermeira Altamira Pereira Valadares conta sua participação na FEB. São Paulo(SP): AMICUS; 2001. p.77- 89.

11. Barreira IA, Baptista SS. A (re)configuração do campo da enfermagem durante o Estado Novo: 1937-1945. Rev Bras Enferm $2002 \mathrm{mar} / \mathrm{abr} ;$ 55( 2): 205-16. quadros, reforçando, assim, o poder simbólico daquelas mulheres em luta de reconhecimento no campo trabalhista, num contexto político-social que relativamente buscou encetar um processo de inclusão de mulheres no campo político durante o Estado Novo. E, ainda, pelo simbolismo envolto à atuação delas para se fazerem ver e para se fazerem crer enfermeiras do Exército, na condição de voluntárias para atuarem na Segunda Guerra Mundial através da Força Expedicionária Brasileira.

Contudo, ao serem desmobilizadas logo após o término da guerra, algumas perdas simbólicas foram estabelecidas por não terem sido aproveitadas em tempo de paz pelo Serviço de Saúde do Exército, fato este que desprestigiou o capital cultural [de enfermagem operativa de guerra] que acumularam por ocasião de sua participação direta no front italiano, reproduzindo, desta forma, aspectos impregnados pela dominação masculina que as violentou simbolicamente ao considerar o gênero feminino como uma ameaça à feminilização das posições ocupadas pelos homens nos postos militares à época.

12. Santos TCF. A câmara discreta e o olhar indiscreto: a persistência da liderança norte-americana no ensino da enfermagem na capital do Brasil:1923-1938. [tese de doutorado]. Escola de Enfermagem Anna Nery/UFRJ; 1998.

13. Pinheiro JJB. A Força Expedicionária Brasileira na $2^{a}$ Guerra Mundial. $2^{\mathrm{a}}$ ed. Rio de Janeiro (RJ): T.A. Nunes Comércio de Livros; 1980.

14. Bourdieu P. A economia das trocas simbólicas. São Paulo (SP): Perspectiva; 2001.

15. Bourdieu P.O poder simbólico. Rio de Janeiro (R): Bertrand Brasil; 1989.

16. A guerra em tempo de paz. Nossa História 2005 jan; 31-35.

17. Bourdieu P. A dominação masculina. Rio de Janeiro (RJ): Bertrand Brasil; 1999.

18. Segalen M. Ritos e rituais contemporâneos. Rio de Janeiro (RJ): FGV; 2002.

19. Perrot M. Mulheres públicas. São Paulo (SP): UNESP; 1998.

\section{Sobre os Autores}

\section{Alexandre Barbosa de Oliveira}

Enfermeiro. Mestre em Enfermagem. Professor do Curso de Graduação em Enfermagem da Universidade Gama Filho. Membro do Núcleo de Pesquisa de História da Enfermagem Brasileira.

\section{Tânia Cristina Franco Santos}

Enfermeira. Doutora em Enfermagem. Professora Adjunta do Departamento de Enfermagem Fundamental da Escola de Enfermagem Anna Nery / Universidade Federal do Rio de Janeiro. Membro do Núcleo de Pesquisa de História da Enfermagem Brasileira. 